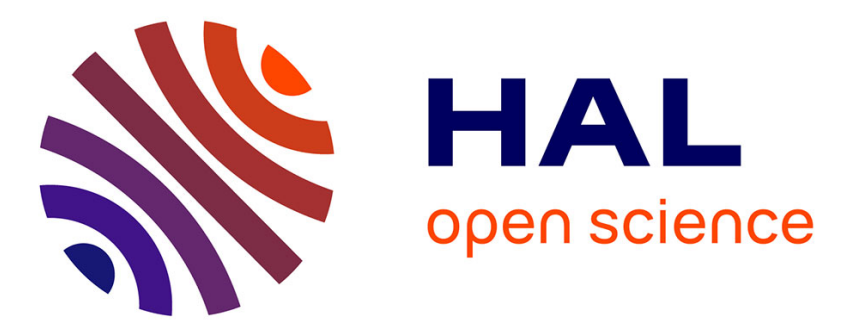

\title{
Solvothermal synthesis, structure and magnetic properties of heterometallic coordination polymers based on a phenolato-oxamato cobidentate-tridentate ligand
} Ang Li, Lise-Marie Chamoreau, Benoît Baptiste, Yanling Li, Yves Journaux, Laurent Lisnard

\section{To cite this version:}

Ang Li, Lise-Marie Chamoreau, Benoît Baptiste, Yanling Li, Yves Journaux, et al.. Solvothermal synthesis, structure and magnetic properties of heterometallic coordination polymers based on a phenolato-oxamato cobidentate-tridentate ligand. Dalton Transactions, 2021, 50, pp.681-688. 10.1039/D0DT03269G . hal-03044725

\author{
HAL Id: hal-03044725 \\ https://hal.science/hal-03044725
}

Submitted on 7 Dec 2020

HAL is a multi-disciplinary open access archive for the deposit and dissemination of scientific research documents, whether they are published or not. The documents may come from teaching and research institutions in France or abroad, or from public or private research centers.
L'archive ouverte pluridisciplinaire HAL, est destinée au dépôt et à la diffusion de documents scientifiques de niveau recherche, publiés ou non, émanant des établissements d'enseignement et de recherche français ou étrangers, des laboratoires publics ou privés. 


\section{Solvothermal synthesis, structure and magnetic properties of heterometallic coordination polymers based on a phenolato-oxamato co- bidentate-tridentate ligand}

Ang Li (李昂), ${ }^{a}$ Lise-Marie Chamoreau, ${ }^{a}$ Benoît Baptiste, ${ }^{b}$ Yanling Li, ${ }^{a}$ Yves Journaux and Laurent Lisnard*a

a-Sorbonne Université, CNRS, Institut Parisien de Chimie Moléculaire, IPCM, F-75252, Paris, France.

b-Sorbonne Université, CNRS, IRD, MNHN, Institut de Minéralogie, de Physique des Matériaux et de Cosmochimie, IMPMC, F-75252, Paris, France

The use of solvothermal conditions has succesfully led to the preparation of heterometallic 1D coordination polymers from a co-bidentate-tridentate phenolato-oxamato ligand. The reaction of the $\mathrm{N}$-(2-hydoxyphenyl)oxamic acid (ohpma) with acetate salts of transition metal ions at $80^{\circ} \mathrm{C}$ has yielded the heterobimetallic [Cu(ohpma)M(OAc)(DMF) $)_{2}(\mathrm{M}=\mathrm{Co}$ (1); $\mathrm{Mn}$ (2)) and the heterotrimetallic $\left[\mathrm{Cu}(\mathrm{ohpma}) \mathrm{Co}_{0.57} \mathrm{Mn}_{0.43}(\mathrm{OAc})(\mathrm{DMF})_{2}\right]$ (3) chain compounds. Single-crystal and powder diffraction studies show that the polymers are isostructural. Magnetic studies suggest the existence of an inter-chain two-dimensional antiferromagnetic interaction taking place in compounds $1-3$.

\section{Introduction}

$\mathrm{N}$-substituted oxamate ligands provide a rich chemistry and prove to be efficient tools in coordination chemistry for the preparation of molecular materials. ${ }^{1-3}$ Looking at aromatic derivatives, rational design has motivated the preparation of numerous ligands that bear bulky, chiral, electro- and photo-active substituents in order to perfect the control over the shape, the dimensionality and the properties of the final edifices. ${ }^{4-6}$ However, the investigation of multipolydentate ligands bearing an additional coordinating group to the oxamate one has been far less looked into. The phenylene-bisoxamate scaffold bearing an additional carboxylato group has been reported to yield homometallic compounds, yet their study has been limited to the metalloligand (Scheme 1a) or revealed synthetic issues in obtaining a fully deprotonated oxamate function (Scheme 1, I-o). ${ }^{7-10}$ In either case, a "whole" coordination of the ligand where all the N/O donor atoms participate was not achieved. A pyridine-based bis-oxamate ligand has permitted the observation of a full coordination mode in the multi-polydentate aromatic oxamate-based ligands family (Scheme 1j), ${ }^{11}$ yet it has also yielded partially binding forms where the pyridine group is free (Scheme 1f, 1k). ${ }^{11,12}$ Similar issues have been observed with the para-substitued phenyloxamate ligands, with either carboxylato or hydroxido additional groups where the oxamate and the additional coordinating groups are only partially or not at all binding (Scheme 1, b-e). ${ }^{13-16}$ On the other hand, the ortho-substituted carboxylato-phenyloxamate ligand has been reported entirely coordinating in homometallic copper-based polymers (Scheme $1 \mathrm{~g}$ ). ${ }^{17}$ These observations led us to 
recently investigate the reactivity of the ortho-subsituted $\mathrm{N}$-(2-hydoxyphenyl)oxamic acid (H $\mathrm{H}_{3}$ ohpma). ${ }^{18}$ We have obtained two homometallic compounds also displaying a whole coordination mode with copper or cobalt ions (Scheme 1h). Nevertheless, we failed at preparing heterometallic systems, and besides the compounds made of $\mathrm{Cu}(\mathrm{II})$ and alkaline earth cations, ${ }^{11}$ none of the compounds reported so far with phenyloxamate-based ligands bearing additional coordinating groups are heterometallic systems. The later are of importance in terms of magnetic properties, and synthetically, one of the key features offered by oxamate chemistry. Indeed, the dissymmetry the bis-bidentate oxamate group facilitates the preparation of heterometallic pairs. Considering that our initial attempts in standard conditions failed in the crystallisation of the heterometallic compounds and not in reacting the ligand, we have envisaged the use of solvothermal conditions. Giving its affinity for the $\kappa \mathrm{N}, \mathrm{\kappa} O$ chelating site of the oxamate ligands, ${ }^{19}$ we assumed that using copper(II) as one of the metal ions would circumvent the one-pot criterion of the solvothermal method. Indeed, a multi-step synthesis is the main strategy on the bench when preparing heterometallic coordination compounds with oxamate ligands. ${ }^{2}$
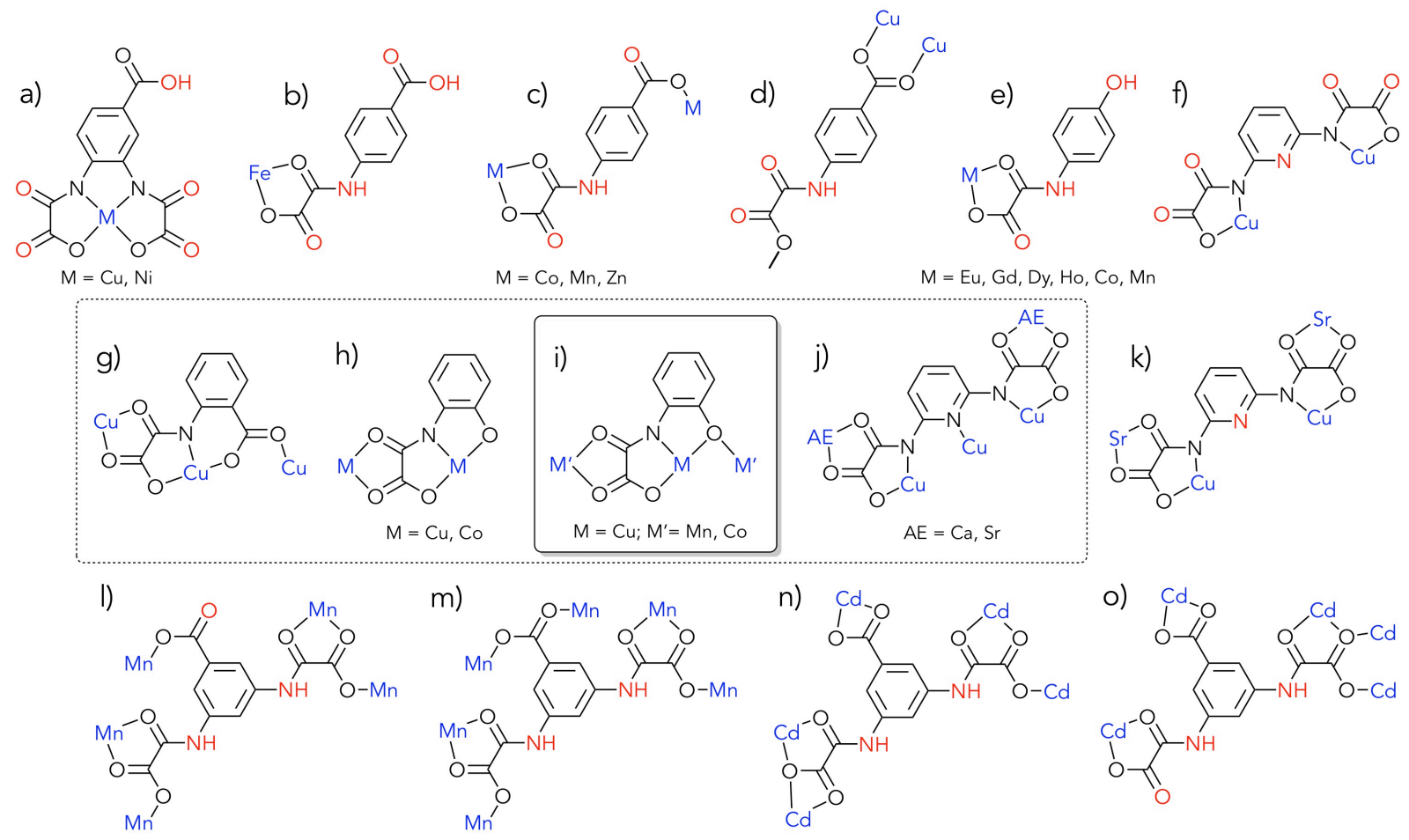

Scheme 1. Drawings of the known coordination modes for oxamate-based multi-polydentate ligands bearing additional coordinating groups.

Our approach was successful, and we present here the solvothermal reaction of the $\mathrm{H}_{3}$ ohpma ligand with transition metal ions. It has yielded a novel 1D polymer in the form of three heterometallic analogues, [Cu(ohpma)Co(OAc)(DMF) 2$]$ (1), [Cu(ohpma)Mn(OAc)(DMF) 2$]$ (2) and $\left[\mathrm{Cu}(\mathrm{ohpma}) \mathrm{Co}_{0.57} \mathrm{Mn}_{0.43}(\mathrm{OAc})(\mathrm{DMF})_{2}\right]$ (3). All the compounds have been characterised by singlecrystal and powder $\mathrm{X}$-ray diffraction, and investigated for their magnetic properties.

\section{Results and discussion}

Compounds 1 and 2 are isostructural and consist of a neutral hetero-bimetallic oxamato-, phenolato- and acetato-bridged chain (Figure 1 ) that crystallizes in the $P 2_{1} / c$ monoclinic space group. The chain is made of [Cu(ohpma)] complexes where the $\mathrm{Cu}^{\prime \prime}$ ion is coordinated to one 
nitrogen atom (N1) and one oxygen atom (O1) of the oxamato group, and the oxygen atom (O4) of the phenolato group. The complexes then bridge the additional $\mathrm{M}^{\prime \prime}$ ions (Co" in $1, \mathrm{Mn}^{\prime \prime}$ in 2 ) in one direction via the remaining chelating carbonyl groups of the oxamate function $(\mathrm{O} 2, \mathrm{O} 3)$, and in the other via the m-oxo atom of the ligand's phenolato group as well as an additional m-acetato bridge $(05,06)$. This coordination mode for the (ohpma) $)^{3-}$ ligand ( $\mu$-oxamato- $\kappa^{2} O, O^{\prime}: \kappa N, k O^{\prime \prime}-\mu$ phenolato, Scheme 1i) differs from the one we have previously observed for homometallic

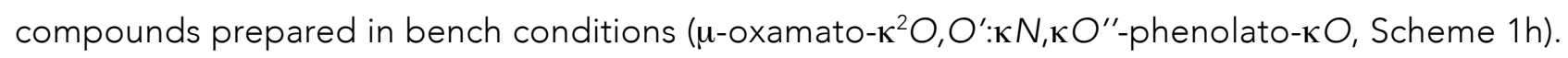
Here, we observe a bridging phenolato oxygen atom instead of a terminal one.

The copper ions are four-coordinate in a square-planar environment with Cu-O distances (1.956 [1.902(1)-2.006(1)]), and Cu-N bond length (1.902(2) and 1.905(1) $\AA$ ) that are comparable to those found in the homometallic 1D polymer, and are indicative of a constrained environment. ${ }^{18}$ The $\mathrm{O} / \mathrm{N}-\mathrm{Cu}-\mathrm{O} / \mathrm{N}$ angles range from 83 to $102^{\circ}$, and the dihedral angle between the $\mathrm{N} 1-\mathrm{Cu}-\mathrm{O} 1$ and the $\mathrm{O} 4-\mathrm{Cu}-\mathrm{O} 5$ planes are of 13 and $12^{\circ}$, for 1 and 2 respectively. The $\mathrm{M}^{\prime \prime}$ ions are six-coordinate, with two DMF molecules completing the coordination sphere. They have fairly regular octahedral environments, with homogeneous M-O distances ranging from 2.061(1) to 2.133(2) $\AA$ for 1 , and from 2.131(2) to 2.206(2) $\AA$ for 2. These distances are similar to previously reported oxamate-based 1D polymers with cis-coordinated $\mathrm{Co}$ " or $\mathrm{Mn}^{\prime \prime}$ ions ${ }^{20-22}$. The O-Co-O angles vary from 79 to $98^{\circ}$, and deviate on average by $4^{\circ}$ from orthogonalilty. For $\mathrm{Mn}^{\prime \prime}$ ions, these angles range from 76 to $100^{\circ}$, with an average deviation of $5^{\circ}$.
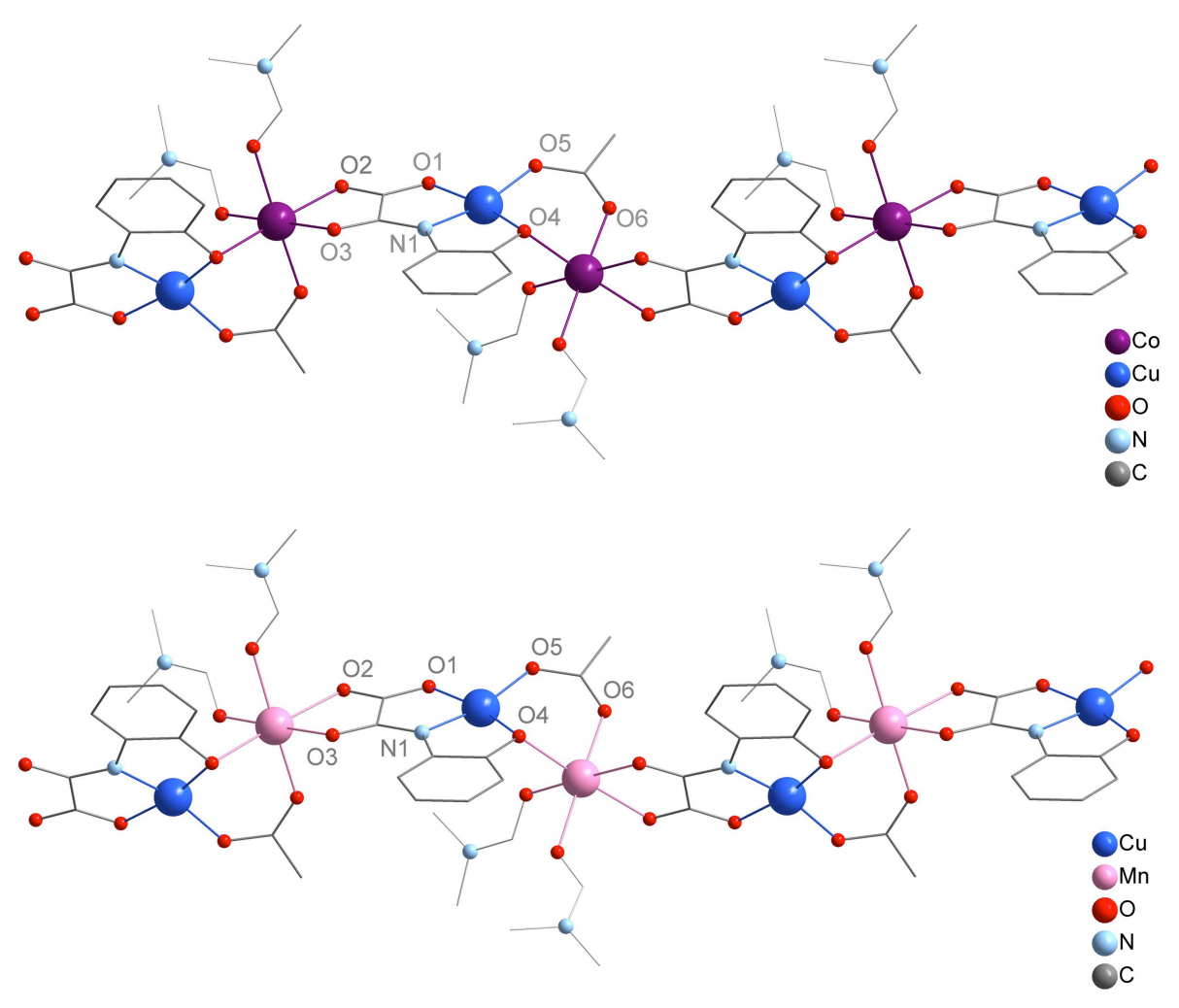

Figure 1. Representation of the heterometallic chains 1 and 2 , with atom labels. $\mathrm{H}$ atoms have been omitted for clarity.

The chains are parallel to each other and aligned along the crystallographic $c$ axis (see supplementary information). The shortest interchain metal-metal distances were found at $7.12 \AA$ (Cu-Co in 1) and $7.15 \AA$ (Cu-Mn in 2). Furthermore, the chains form sheets perpendicular to the 
crystallographic a axis (Figure 2). These layers of chains are alternatively separated by aromatic rings and DMF molecules and the resulting distances between mean planes of magnetic ions are $8.46 \AA$ (8.43 in 2) and $6.69 \AA$ (6.58 in 2).

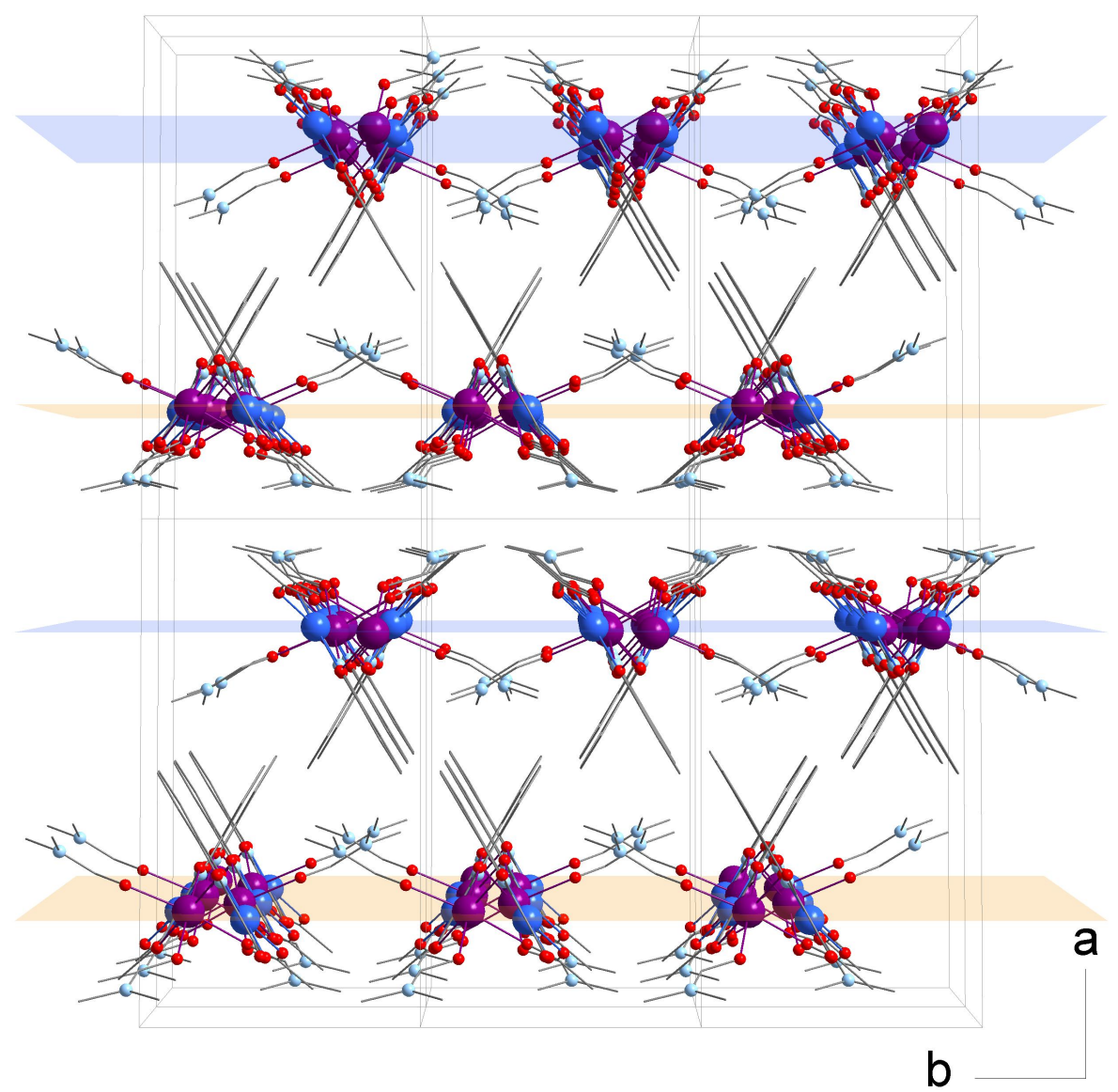

Figure 2. Representation of the layers of chains in $1 . \mathrm{H}$ atoms have been omitted for clarity.

To further investigate the magnetic properties, we have introduced manganese ions in the synthesis of the $\left[\mathrm{Cu}(\mathrm{ohpma}) \mathrm{Co}(\mathrm{OAc})(\mathrm{DMF})_{2}\right]$ chain. This has led us to the following heterotrimetallic compound: [Cu(ohpma)Co.57 $\mathrm{Mn}_{0.43}(\mathrm{OAc})(\mathrm{DMF})_{2}$ ] (3). Single-crystal data (see Table 2 in the Experimental section) and Le Bail refinement of the powder X-ray patterns (Table 2 and Figure 3) performed on the bulks of compounds 1-3 confirm that all three chains are isostructural. The differences that are observed between the experimental X-ray powder diffraction diagrams reflect the small differences observed with the single-crystal crystallographic parameters. Furthermore, the Le Bail refinements indicate mainly a slight increase of the unit cell parameter a at room temperature, which could be consistent with the packing of the chains in the solid. The metal content in the formula of compound 3 was taken from ICP-AES results and differ from the singlecrystal X-Ray data. In the latter, and giving the quality of the data set, site occupancies for the Co and $\mathrm{Mn}$ atoms were refined and gave on the measured crystal $\left\{\mathrm{CO}_{0.8} \mathrm{Mn}_{0.2}\right\}$ for 3 . A second set of ICP-AES titration confirmed the ratio given in the formula and was $\left\{\mathrm{CO}_{0.56} \mathrm{Mn}_{0.44}\right\}$. 


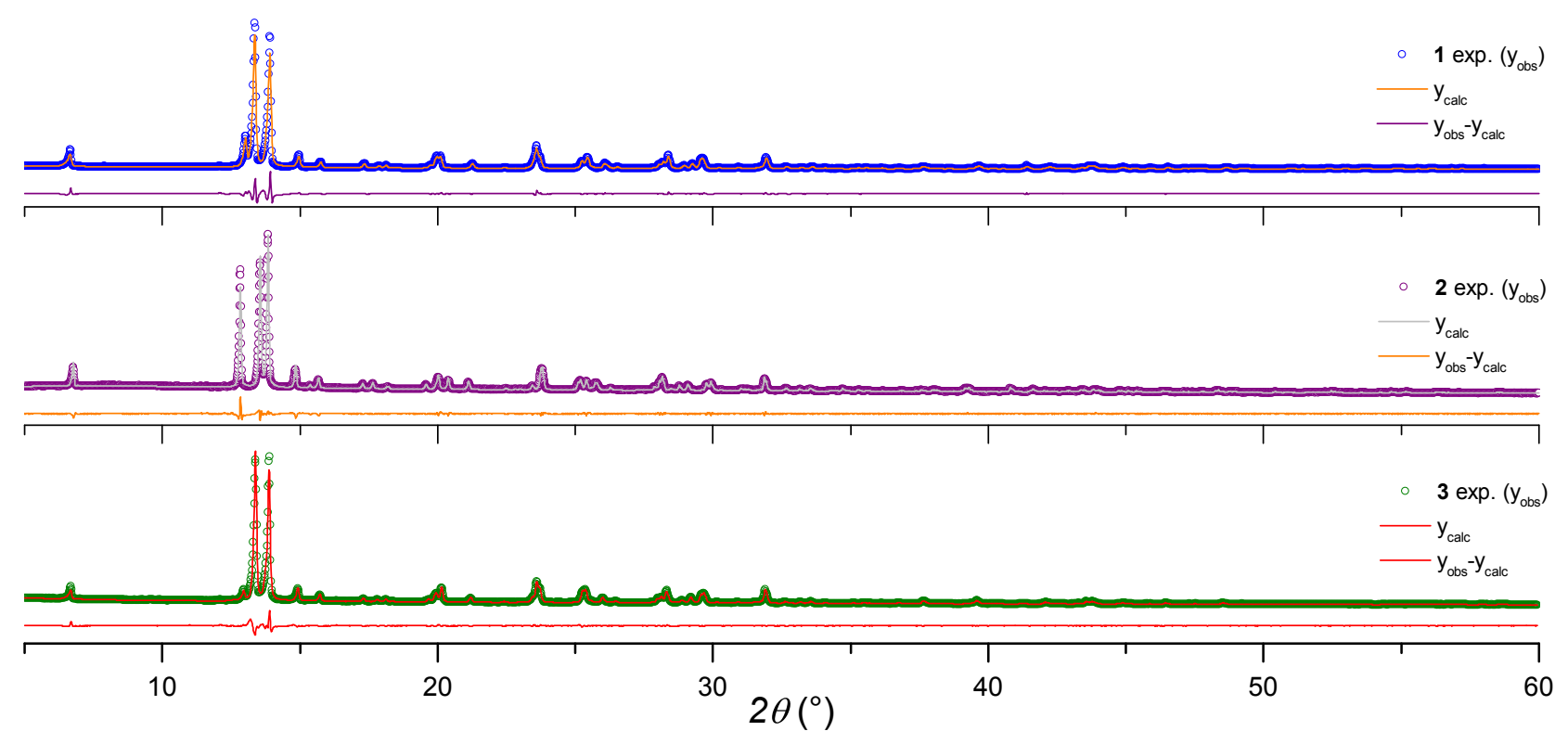

Figure 3. Experimental and refined powder patterns for compounds 1-3.

The DC magnetic properties of compounds $1-3$ in the form of $\chi_{M} T$ versus $T$ plots are shown in Figure 3. The value of $\chi_{M} T$ for compounds 1 is within the theoretical range, assuming noninteracting ions (see Table 1). In the presence of $\mathrm{Mn}^{\prime \prime}$ however, these values are below the theoretical limit, pointing at the existence of a strong antiferromagnetic interaction in 2 and 3 , or at least, stronger than in 1.

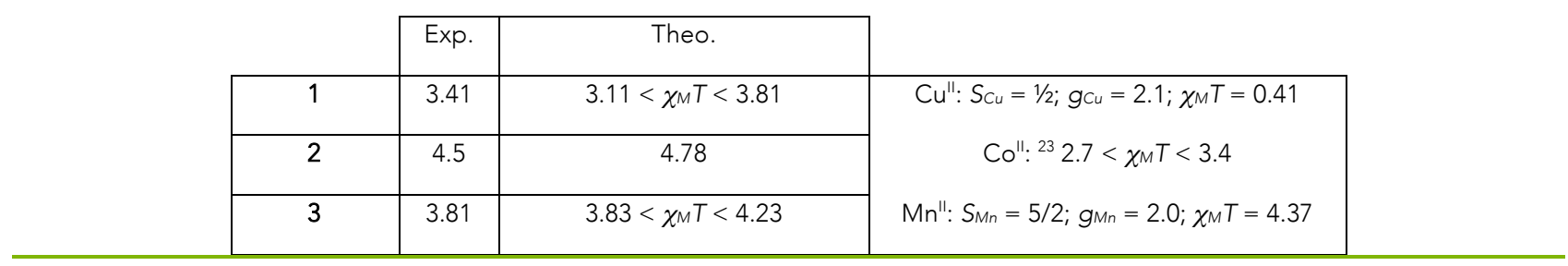

Table 1. Experimental and theoretical CMT values $\left(\mathrm{cm}^{3} \mathrm{Kmol}^{-1}\right)$ for 1-3.

The existence of antiferromagnetic interactions is supported by the temperature dependence of the $\chi_{M} T$ products, which, in all cases, continuously decrease from 300 to $60 \mathrm{~K}$ (Figure 3). In the case of 2, $\chi_{\mathrm{M}} T$ reaches a minimum at $60 \mathrm{~K}$, with a value of $3.88 \mathrm{~cm}^{3} \mathrm{Kmol}^{-1}$, before increasing sharply up to $16.85 \mathrm{~cm}^{3} \mathrm{Kmol}^{-1}$ at $2 \mathrm{~K}$. For 3 , the decrease of $\chi_{\mathrm{M}} T$ continues from $60 \mathrm{~K}$ to $18 \mathrm{~K}$ where a plateau at $2.05 \mathrm{~cm}^{3} \mathrm{Kmol}^{-1}$ is reached. The $\chi_{\mathrm{M}} T$ product then slightly increases to $2.20 \mathrm{~cm}^{3} \mathrm{Kmol}^{-1}$ at $4.5 \mathrm{~K}$ before reaching 2.11 at $2 \mathrm{~K}$. The $\chi_{M} T$ product of 1 keeps decreasing below $60 \mathrm{~K}$, down to 0 $\mathrm{cm}^{3} \mathrm{Kmol}^{-1}$ at $2 \mathrm{~K}$. A small field-dependent contribution was observed at $15 \mathrm{~K}$ in the heterobimetallic chain 1 . This is confirmed by the presence of two weak anomalies in the zerofield-cooled and field-cooled (ZFC/FC) magnetisation curves at $15 \mathrm{~K}$ and $5.5 \mathrm{~K}$ that are due to the presence of small amounts of magnetic phases showing a ferromagnetic ordering. This behaviour is attributed to trace amounts of a non stoichiometric cobalt hydrate hydroxide impurity, that presents a magnetic ordering in this temperature range and are unfortunately often observed 
when performing low field measurements on cobalt(II)-based compounds (see supplementary information). ${ }^{24}$

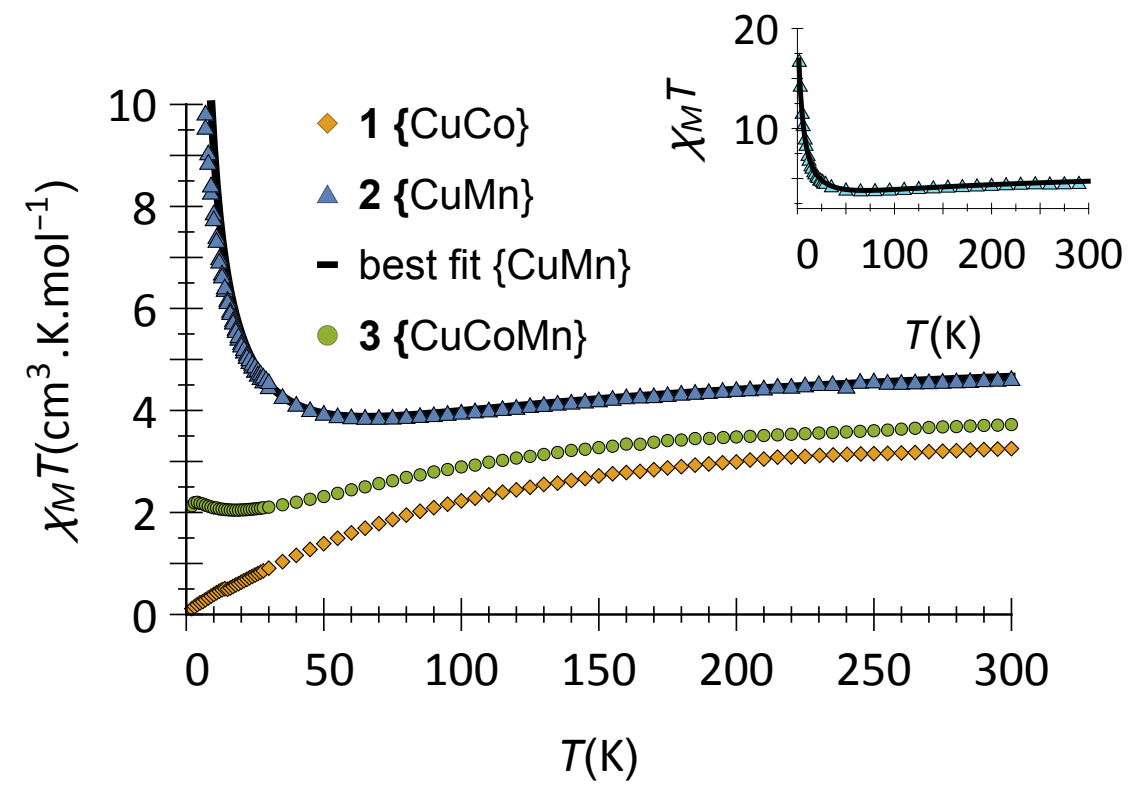

Figure 4. Thermal dependence of the $c_{M} T$ products of 1-3, measured at $5000 \mathrm{Oe}(T>200 \mathrm{~K})$ and $200 \mathrm{Oe}(\mathrm{T}<200 \mathrm{~K})$, the solid line represents the best fit for 2 . Inset shows the full temperature range for 2 .

In 2, the presence of a minimum is characteristic of a ferrimagnetic $\left\{\mathrm{Mn}^{\prime \prime}-\mathrm{Cu}\right.$ " $\}$ chain compound. ${ }^{25-27}$ However, there is no minimum and increase of the $\chi_{M} T$ product at low temperature for the $\{\mathrm{CuCo}\}$ chain 1 . This is in stark contrast with the oxamato-bridged bimetallic $\{\mathrm{CuCo}\}$ chains reported in the literature. ${ }^{28-31}$ For the trimetallic chain 3, the $\chi_{M} T$ product steadily decreases but reaches a minimum around $20 \mathrm{~K}$, before going up. We assume that it comes from the presence of $\mathrm{Mn}$ " ions with a larger magnetic moment that reinforce the ferrimagnetic character of the chain.

Unfortunately, it is only possible to model the magnetic properties of the $\{\mathrm{CuMn}\}$ chain for which a theoretical alternating chain model has been developed using the following Hamiltonian for the interaction: ${ }^{32,33}$

$H=-J \sum_{i} S_{B_{i}}\left[(1+\alpha) S_{A_{i}}+(1-\alpha) S_{A_{i+1}}\right]$

The least square fitting of the experimental data were done in the 22-300 $\mathrm{K}$ temperature range to avoid the effect of interchain interactions. The best fit parameters are equal to $\mathrm{J}=-22.0 \mathrm{~cm}^{-1}, \alpha=$ 0.59 and $g_{c_{u}}=2.14$, with an agreement factor of $4.7 * 10^{-5}$. This corresponds to $J_{\text {oxa }}=-35 \mathrm{~cm}^{-1}$ and $J_{\text {hydro }}=-9.0 \mathrm{~cm}^{-1}$. The largest value is attributed to the interaction between the $\mathrm{Cu}^{\prime \prime}$ and $\mathrm{Mn}$ " ions through the oxamato bridge and in accordance with the reported values. ${ }^{26,27,34}$

There is no model for a $\{\mathrm{CuCO}\}$ alternating chain. However, Drillon et al. have developed a model for a regular chain that takes into account spin-orbit coupling. ${ }^{28}$ In this model -even for small values of the $\mathrm{Cu}^{\prime \prime}-\mathrm{CO}^{\prime \prime}$ interaction- a minimum of $\chi_{\mathrm{M}} T$ is expected, which gives no satisfactory explanation to the absence of a minimum in 1 . The only possible explanation would be substantial antiferromagnetic interchain interactions, although it seems unlikely owing to the crystal structure 
with well isolated chains (shortest interchain metal-metal distances were found at $7.12 \AA$ (Cu-Co) and $7.15 \AA$ (Cu-Mn)).

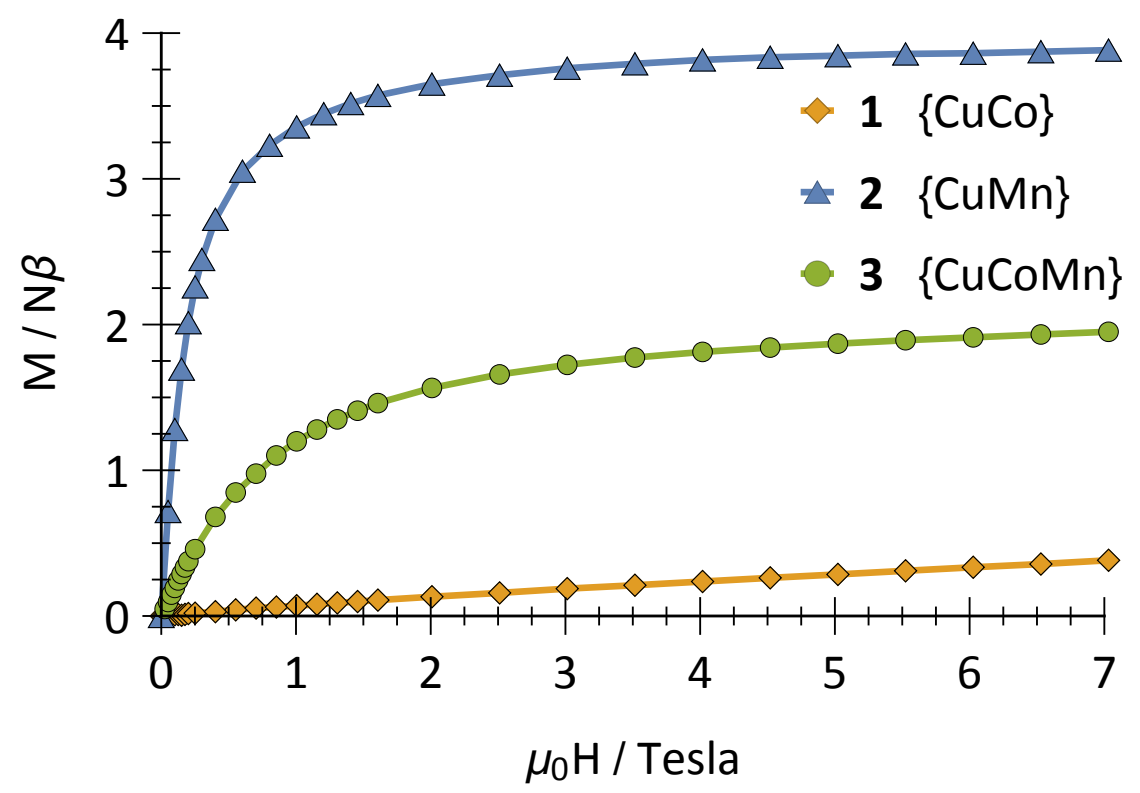

Figure 5. Magnetisation v. field measured at $2 \mathrm{~K}$ and between 0 and $7 \mathrm{~T}$ for compounds $1-3$. The lines are eye guides.

The $M$ versus $H$ plots for compounds $1-3$ at $2.0 \mathrm{~K}$ are shown in Figure 4 . For compound 2 the saturated magnetisation value at $7 \mathrm{~T}$ is $3.9 \mathrm{Nm}_{\mathrm{B}}$, which is consistent for an $S=2$ ground state for the basic $\{\mathrm{CuMn}\}$ unit resulting from antiferromagnetic coupling between the $\mathrm{Mn}^{\prime \prime}$ and $\mathrm{Cu}^{\prime \prime}$ ions in 2. The $M$ versus $H$ curve of 1 is more puzzling. Even at $7 T$, the $M$ value is only $0.38 N \mu_{B}$ and the variation of $M$ with the magnetic field is almost linear. It resembles the variation of an antiferromagnetic phase and the presence of a magnetic order would actually be consistent with the evolution of the $\chi_{M} T$ product with the temperature, which tends towards zero at low temperature. Again, this is puzzling considering the structure of the compound with isolated chains in the crystal. Moreover, since this compound is isostructural with 2, it would be difficult to understand why compound 2 behaves as an isolated ferrimagnetic chain while 1 presents an antiferromagnetic order. To check whether the chains are actually isolated in compound 2 , the fit of $\chi_{M} T$ versus temperature for 2 was repeated on the whole range of temperature including a Curie-Weiss law in the model to take into account the interchain interaction. The best-fit parameters are equal to $\mathrm{J}=-23 \mathrm{~cm}^{-1}, \alpha=0.37, g_{\mathrm{cu}}=2.10$ and $\theta=-5.9 \mathrm{~K}$, with an agreement factor of $1.56^{*} 10^{-3}$. The high negative value for $\theta$ in compound 2 supports the hypothesis of a nonnegligible antiferromagnetic interchain interaction. The lack of obvious exchange interaction pathways between the chains indicates that the interactions are probably dipolar. However, these non-negligible interactions do not result in a magnetic ordering in the case of compound 2. One plausible explanation is that the interactions develop only in two dimensions. This is consistent with the structure where the chains are organised in layers in the bc plane (see Figure 2). This excludes a magnetic order for compound 2 that contains isotropic $\mathrm{Mn}$ " ions while the presence of Ising type Coll ions in 1 could lead to an antiferromagnetic order (see supplementary information) $)^{35}$. Furthermore, this is coherent with the observed magnetisation curves for 3 . The introduction of an isotropic ion suppresses the crossover toward an Ising-type behaviour for the 
chain, and it prevents the magnetic ordering. The last point to address is the lack of a maximum in the $\chi_{\mathrm{M}} v$. $T$ plot of 1 -i.e. a signature of antiferromagnetic ordering (see supplementary information). The presence of the cobalt hydroxide impurity most likely masks the occurrence of a maximum of $\chi_{\mathrm{M}}{ }^{24}$

\section{Experimental}

All reagents were used as purchased with no further purification. The $\mathrm{N}$-(2-hydoxyphenyl)oxamic acid hydrate, mixed sodium salt $\left(\mathrm{H}_{2.5} \mathrm{Na}_{0.5}\right.$-ohpma.0.5 $\left.\mathrm{H}_{2} \mathrm{O}\right)$ was prepared following the reported procedure. $^{18}$

\section{Synthesis.}

[Cu(ohpma)Co(OAc)(DMF) $)_{2}$ (1). $\mathrm{H}_{2.5} \mathrm{Na}_{0.5}$-ohpma.0.5 $\mathrm{H}_{2} \mathrm{O}(0.5 \mathrm{mmol}, 0.100 \mathrm{~g}), \mathrm{Cu}(\mathrm{OAc})_{2} \cdot \mathrm{H}_{2} \mathrm{O}$ $(0.5 \mathrm{mmol}, 0.099 \mathrm{~g})$ and $\mathrm{Co}(\mathrm{OAc})_{2} .4 \mathrm{H}_{2} \mathrm{O}(0.5 \mathrm{mmol}, 0.124 \mathrm{~g})$ were placed in a $23 \mathrm{~mL}$ Teflon-lined autoclave reactor filled with DMF $(3 \mathrm{~mL})$ and $\mathrm{H}_{2} \mathrm{O}(1 \mathrm{~mL})$. The reactor was heated to $80^{\circ} \mathrm{C}$ in $2 \mathrm{~h}$, kept at this temperature for $72 \mathrm{~h}$ and then cooled down to room temperature in $24 \mathrm{~h}$. Dark green block crystals of 1 were collected and washed with DMF. Yield: $0.190 \mathrm{~g}, 89.6 \%$ (based on Cu; $\mathrm{M}=505.8 \mathrm{gmol}^{-1}$ ). Elemental analysis (\%): calc. for $\mathrm{C}_{16} \mathrm{H}_{21} \mathrm{CuCoN}_{3} \mathrm{O}_{8}: \mathrm{C}, 37.99 ; \mathrm{H}, 4.18 ; \mathrm{N}, 8.31$; Co, 11.65; Cu, 12.56 (wt. Cu/Co: 1.08). Found: C, 37.83; H, 4.20; N, 8.16; Co, 10.09; Cu, 11.31 (wt. $\mathrm{Cu} / \mathrm{Co}: 1.12)$. Selected IR data $\left(\mathrm{cm}^{-1}\right):$ 2932(m), 1627(s), 1566(s), 1473(s), 1370(m), 1344(s), 1297(m), 1274(s), 1242(s), 1110(m), 1027(m), 972(w), 932(w), 886(s), 786(w), 750(s), 675(s), 565(m), 534(m), 373 (m), 325(s).

[Cu(ohpma)Mn(OAc)(DMF) 2 ] (2). $\mathrm{H}_{2.5} \mathrm{Na}_{0.5}$-ohpma.0.5 $\mathrm{H}_{2} \mathrm{O}$ (0.5 mmol, $\left.0.100 \mathrm{~g}\right), \mathrm{Cu}(\mathrm{OAc})_{2} \cdot \mathrm{H}_{2} \mathrm{O}$ $(0.5 \mathrm{mmol}, 0.099 \mathrm{~g})$ and $\mathrm{Mn}(\mathrm{OAc})_{2} .4 \mathrm{H}_{2} \mathrm{O}(0.5 \mathrm{mmol}, 0.116 \mathrm{~g})$ were placed in a $23 \mathrm{~mL}$ Teflon-lined autoclave reactor filled with DMF $(4 \mathrm{~mL})$. The reactor was heated to $80^{\circ} \mathrm{C}$ in $2 \mathrm{~h}$, kept at this temperature for $72 \mathrm{~h}$ and then cooled down to room temperature in $24 \mathrm{~h}$. Dark green block crystals of 2 were collected and washed with DMF. Yield: $0.131 \mathrm{~g}, 62.4 \%$ (based on $\mathrm{Cu}, \mathrm{M}=501.8$ gmol $^{-1}$ ). Elemental analysis (\%): calc. for $\mathrm{C}_{16} \mathrm{H}_{21} \mathrm{CuMnN}_{3} \mathrm{O}_{8}: \mathrm{C}, 38.29 ; \mathrm{H}, 4.22 ; \mathrm{N}, 8.37 ; \mathrm{Mn}, 10.94 ; \mathrm{Cu}$, 12.66 (wt. $\mathrm{Cu} / \mathrm{Mn}=1.16$ ). Found: $\mathrm{C}, 38.11 ; \mathrm{H}, 4.24 ; \mathrm{N}, 8.19 ; \mathrm{Mn}, 11.72 ; \mathrm{Cu}, 13.53$ (wt. $\mathrm{Cu} / \mathrm{Mn}=1.15)$. Selected IR data $\left(\mathrm{cm}^{-1}\right):$ 2932(m), 1627(s), 1562(s), 1472(m), 1416(m), 1371(s), 1342(w), 1296(m), 1274(m), 1242(m), 1150(m), 1105(m), 1061(m), 1027(m), 931(w), 838(s), 784(m), 750(m), 670(m), 593 $(\mathrm{m}), 563(\mathrm{~s}), 533(\mathrm{~m}), 446(\mathrm{~m}), 362(\mathrm{~m}), 327(\mathrm{~m}), 285(\mathrm{~m})$.

[Cu(ohpma)Co $\left.0.57 \mathrm{Mn}_{0.43}(\mathrm{OAc})(\mathrm{DMF})_{2}\right]$ (3). $\mathrm{H}_{2.5} \mathrm{Na}_{0.5}$-ohpma. $0.5 \mathrm{H}_{2} \mathrm{O}$ (0.5 mmol, 0.100 g), $\mathrm{Cu}(\mathrm{OAc})_{2} . \mathrm{H}_{2} \mathrm{O}(0.5 \mathrm{mmol}, 0.099 \mathrm{~g}), \mathrm{Co}(\mathrm{OAc})_{2} .4 \mathrm{H}_{2} \mathrm{O}(0.25 \mathrm{mmol}, 0.062 \mathrm{~g})$ and $\mathrm{Mn}(\mathrm{OAc})_{2} .4 \mathrm{H}_{2} \mathrm{O}(0.25$ $\mathrm{mmol}, 0.058 \mathrm{~g}$ ) were placed in a $23 \mathrm{~mL}$ Teflon-lined autoclave reactor filled with DMF (3 mL) and $\mathrm{H} 2 \mathrm{O}(1 \mathrm{~mL})$. The reactor was heated to $80^{\circ} \mathrm{C}$ in $2 \mathrm{~h}$, kept at this temperature for $72 \mathrm{~h}$ and then cooled down to room temperature in $24 \mathrm{~h}$. The resulting green solution was then left to crystallise at room temperature in a sealed vial. After 1 day, dark crystals of 3 were collected and washed with DMF. Yield: $0.179 \mathrm{~g}, 85 \%$ (based on $\mathrm{Cu}, \mathrm{M}=504.1 \mathrm{gmol}^{-1}$ ). Elemental analysis (\%): calc. for

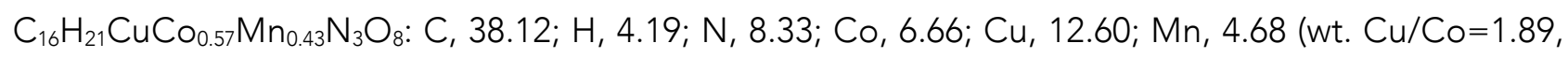
$\mathrm{Cu} / \mathrm{Mn}=2.69 ; \mathrm{Co} / \mathrm{Mn}=1.42$ ). Found: $\mathrm{C}, 37.54 ; \mathrm{H}, 4.01 ; \mathrm{N}, 8.19 ; \mathrm{Mn}, 4.19 ; \mathrm{Co}, 5.99 ; \mathrm{Cu}, 11.44$ (wt. $\mathrm{Cu} / \mathrm{Co}=1.91, \mathrm{Cu} / \mathrm{Mn}=2.73 ; \mathrm{Co} / \mathrm{Mn}=1.43)$. Selected IR data $\left(\mathrm{cm}^{-1}\right): 2930(\mathrm{w}), 1628(\mathrm{~s}), 1565(\mathrm{~s}), 1472(\mathrm{~m})$, $1371(\mathrm{~m}), 1343(\mathrm{~s}), 1296(\mathrm{~m}), 1274(\mathrm{~s}), 1242(\mathrm{~s}), 1109(\mathrm{~m}), 1027(\mathrm{~m}), 950(\mathrm{w}), 885(\mathrm{~s}), 785(\mathrm{w}), 750(\mathrm{~s}), 673(\mathrm{~s})$, 564(m), 534(m), $457(\mathrm{~m})$. 


\section{Magnetic measurements.}

Magnetic measurements in dc mode were performed on the polycrystalline samples of 1-3 restrained within a capsule with a Quantum Design MPMS SQUID. Magnetic susceptibility data were corrected for the diamagnetism of the constituent atoms using the Pascal's constants. The diamagnetism of the sample holder was measured and subtracted from the raw data.

\section{Elemental analysis.}

Elemental analysis was performed in the "service de microanalyse" at ICSN (CNRS, Gif/Yvette, France) and via the PARI program at the IPGP (Paris, France).

\section{FT-IT and TGA.}

ATR/FT-IR spectra were collected on a Bruker TENSOR 27 equipped with a simple reflexion ATR diamond plate of the Harrick MPV2 series. The thermogravimetric analysis (TGA) was performed on a TA Instruments SDTQ600 under air or nitrogen with a heating rate of $5^{\circ} \mathrm{C} / \mathrm{min}$.

\section{Crystallography.}

Single-crystal X-Ray diffraction. The data collections for 1-3 were carried out on a Bruker Kappa-APEX II CCD diffractometers. Crystals were mounted on a Hampton Research cryoloop using Paratone-N oil and placed in the cold flow produced with an Oxford Cryosystems device. Data collection strategies were generated with the APEX2 suite of programs (BRUKER). ${ }^{36}$ The refinement of the unit cell parameters and data reduction were carried out with SAINT (BRUKER), ${ }^{36}$ and absorptions were corrected with SADABS. ${ }^{36,37}$ The structures were solved with SHELXT-14 ${ }^{38}$ and refined with the SHELXL-2014/7 program $^{39}$ in the OLEX2 software. ${ }^{40}$ Crystallographic parameters and data refinement results for 1-3 are given in Table 2. CCDC-2032124-2032126 contain the supplementary crystallographic data for this paper. The data can be obtained free of charge from The Cambridge Crystallographic Data Centre via www.ccdc.cam.ac.uk/structures

Powder X-ray diffraction. The X-ray powder diffraction (XRD) patterns were collected at the Xray diffraction platform of the IMPMC, from samples deposited on zero background silicon holders, using an X'Pert Pro MPD Panalytical diffractometer in Bragg-Brentano geometry equipped with a Co-K $\alpha$ radiation source $\left(\lambda_{K_{a} 1}=1.78897 \AA, \lambda_{K_{a} 2}=1.79285 \AA\right)$ and an $X^{\prime}$ Celerator detector. Le Bail refinements ${ }^{41}$ were performed with the FullProf suite of programs. ${ }^{42}$ 


\begin{tabular}{|c|c|c|c|c|c|c|}
\hline & 1 & $\begin{array}{l}\text { Powder XRD } \\
\text { Le Bail } \\
\text { refinement }\end{array}$ & 2 & $\begin{array}{c}\text { Powder XRD } \\
\text { Le Bail refinement }\end{array}$ & 3 & $\begin{array}{l}\text { Powder XRD } \\
\text { Le Bail } \\
\text { refinement }\end{array}$ \\
\hline Formula & $\mathrm{C}_{16} \mathrm{H}_{21} \mathrm{CuCoN} \mathrm{O}_{8}$ & & $\mathrm{C}_{16} \mathrm{H}_{21} \mathrm{CuMnN}_{3} \mathrm{O}_{8}$ & & $\begin{array}{c}\mathrm{C}_{16} \mathrm{H}_{21} \mathrm{CuCo} 0.78 \mathrm{Mn}_{0.22} \mathrm{~N}_{3} \\
\mathrm{O}_{8}\end{array}$ & \\
\hline $\mathrm{FW}\left[\mathrm{g} \mathrm{mol}^{-1}\right]$ & 505.83 & & 501.84 & & 504.94 & \\
\hline Crystal system & Monoclinic & Monoclinic & Monoclinic & Monoclinic & Monoclinic & Monoclinic \\
\hline Space group & $P 2{ }_{1} / C$ & $P 2_{1} / C$ & $P 2_{1} / c$ & $P 2{ }_{1} / C$ & $P 2{ }_{1} / c$ & $P 2{ }_{1} / c$ \\
\hline$a[\AA ̊]$ & $15.3056(4)$ & $15.5124(3)$ & $15.1715(7)$ & $15.3346(2)$ & $15.2626(4)$ & $15.4925(2)$ \\
\hline$b[\AA]$ & $8.3802(2)$ & $8.4173(1)$ & $8.4796(4)$ & $8.5205(1)$ & $8.4325(2)$ & $8.44424(8)$ \\
\hline$c[\AA]$ & $15.8983(4)$ & $15.9123(4)$ & $16.1749(7)$ & $16.1908(2)$ & $16.0027(4)$ & $15.9995(5)$ \\
\hline$\beta\left[^{\circ}\right]$ & $98.204(1)$ & $97.997(2)$ & $98.443(3)$ & $98.372(2)$ & $98.2690(10)$ & $98.085(2)$ \\
\hline$V\left[\AA^{3}\right]$ & $2018.31(9)$ & $2057.51(7)$ & $2058.32(16)$ & $2091.92(4)$ & $2038.17(9)$ & $2064.78(7)$ \\
\hline Z & 4 & & 4 & & 4 & \\
\hline$T[\mathrm{~K}]$ & $200(2)$ & 298 & $200(2)$ & 298 & $200(2)$ & 298 \\
\hline$\lambda[\AA]$ & $1.54178(\mathrm{Cu}-\mathrm{K} \alpha)$ & $1.789190(\mathrm{Co}-\mathrm{K} \alpha)$ & 0.71073 (Mo-K $\alpha)$ & $1.789190(\mathrm{Co}-\mathrm{K} \alpha)$ & $1.54178(\mathrm{Cu}-\mathrm{K} \alpha)$ & 1.789190 (Co-K $\alpha)$ \\
\hline$\rho_{\text {calc }}\left[\mathrm{g} \mathrm{cm}^{-3}\right]$ & 1.665 & & 1.619 & & 1.646 & \\
\hline$\mu\left[\mathrm{mm}^{-1}\right]$ & 8.180 & & 1.694 & & 7.803 & \\
\hline$F(000)$ & 1032 & & 1024 & & 1030 & \\
\hline Crystal size [mm] & $0.15 \times 0.12 \times 0.08$ & & $0.12 \times 0.11 \times 0.08$ & & $0.22 \times 0.2 \times 0.12$ & \\
\hline$q$ limits $\left[{ }^{\circ}\right]$ & $5.841-67.725$ & $4.111-70$ & $1.357-30.095$ & $4.111-70$ & $5.859-68.294$ & 4.111-59.99 \\
\hline Measured reflections & 27128 & & 17547 & & 17152 & \\
\hline Unique reflections & 3637 & & 6040 & & 3725 & \\
\hline$R_{\text {int }}$ & 0.034 & & 0.053 & & 0.0309 & \\
\hline Reflections $\mid>2 \sigma(l)$ & 3541 & & 3797 & & 3437 & \\
\hline Parameters & 267 & & 267 & & 268 & \\
\hline Restraints & 0 & & 0 & & 0 & \\
\hline$R_{1}[I>2 \sigma(I)] / R_{p}$ & 0.0267 & 0.122 & 0.0412 & 0.136 & 0.0277 & 0.113 \\
\hline$w R_{2} / R_{w p}$ & 0.0714 & 0.147 & 0.0829 & 0.109 & 0.0696 & 0.121 \\
\hline GOF & 1.018 & & 0.969 & & 1.047 & \\
\hline $\begin{array}{c}\text { Largest residuals } \\
{\left[\mathrm{e} \AA^{3}\right]}\end{array}$ & $-0.547 ; 0.338$ & & $-0.359 ; 0.418$ & & $-0.261 ; 0.363$ & \\
\hline$R_{1}=\frac{\sum|| F_{o}|-| F_{c}||}{\sum\left|F_{o}\right|}$ & $R_{p}=\frac{\sum\left|y_{0}-y_{c}\right|}{\sum y_{0}}$ & $\omega R_{2}=\sqrt{\frac{\sum(\omega}{\sum}}$ & $\frac{\left.\omega\left(F_{o}^{2}-F_{c}^{2}\right)^{2}\right)}{\left(\omega\left(F_{o}^{2}\right)^{2}\right)}$ & $R_{w p}=\sqrt{\frac{\sum\left(\omega\left(y_{o}^{2}-y_{c}^{2}\right)\right)}{\sum\left(\omega\left(y_{o}^{2}\right)^{2}\right)}}$ & & \\
\hline
\end{tabular}

Table 2. Crystallographic parameters and data refinement for compound 1-3.

\section{Conclusions}

New neutral heterometallic oxamate-based 1D compounds have been successfully synthesized from an ortho-substituted phenyloxamate ligand with an hydroxido group. They represent the first examples of 1D oxamate-based coordination polymers obtained solvothermally, and more generally, the first examples of compounds with fully coordinating oxamate ligands prepared solvothermally. In comparison to the multi-step approach traditionally used for oxamate chemistry, the one-pot method used here has not been an issue for the preparation of heterobimetallic compounds. It has even been possible to prepare an heterotrimetallic chain. This is made possible by the strong affinity of copper ions for the $\kappa N, \kappa O$ chelating site of the oxamate ligands. As such, copper-based heterometallic systems represent ideal targets for the solvothermal preparation of oxamate-based magnetic coordination polymers.

\section{Acknowledgements}

This work was supported by the Ministère de l'Enseignement Supérieur, de la Recherche et de I'Innovation (MESRI), the Centre National de la Recherche Scientifique (CNRS) and the China 
Scholarship Council (CSC) with M. Ang Li's PhD fellowship. Elemental analysis was supported by the IPGP multidisciplinary program PARI, and by Paris-IdF region SESAME Grant no. 12015908.

\section{Notes and references}

1 O. Kahn, Acc. Chem. Res., 2000, 33, 647-657.

2 E. Pardo, R. Ruiz-Garcia, J. Cano, X. Ottenwaelder, R. Lescouëzec, Y. Journaux, F. Lloret and Miguel. Julve, Dalton Trans., 2008, 2780-2805.

3 T. Grancha, J. Ferrando-Soria, M. Castellano, M. Julve, J. Pasán, D. Armentano and E. Pardo, Chem. Commun., 2014, 50, 7569-7585.

4 M. Castellano, R. Ruiz-García, J. Cano, J. Ferrando-Soria, E. Pardo, F. R. Fortea-Pérez, S.-E. Stiriba, M. Julve and F. Lloret, Acc. Chem. Res., 2015, 48, 510-520.

5 M. Castellano, R. Ruiz-García, J. Cano, J. Ferrando-Soria, E. Pardo, F. R. Fortea-Pérez, S.-E. Stiriba, W. P. Barros, H. O. Stumpf, L. Cañadillas-Delgado, J. Pasán, C. Ruiz-Pérez, G. de Munno, D. Armentano, Y. Journaux, F. Lloret and M. Julve, Coord. Chem. Rev., 2015, 303, 110-138.

6 Y. Journaux, J. Ferrando-Soria, E. Pardo, R. Ruiz-Garcia, M. Julve, F. Lloret, J. Cano, Y. Li, L. Lisnard, P. Yu, H. Stumpf and C. L. M. Pereira, Eur. J. Inorg. Chem., 2018, 2018, 228-247.

7 C. O. Paul-Roth, Comptes Rendus Chimie, 2005, 8, 1232-1236.

8 K. Rühlig, R. Mothes, A. Aliabadi, V. Kataev, B. Büchner, R. Buschbeck, T. Rüffer and H. Lang, Dalton Trans., 2016, 45, 7960-7979.

9 A. Conte-Daban, V. Borghesani, S. Sayen, E. Guillon, Y. Journaux, G. Gontard, L. Lisnard and C. Hureau, Anal. Chem., 2017, 89, 2155-2162.

10 L. Hou, L.-N. Ma, X.-Y. Li, Y.-Z. Li, W.-J. Shi, G. Liu and Y.-Y. Wang, ChemPlusChem, 2019, 84, 62-68.

11 T. S. Fernandes, W. D. C. Melo, L. H. G. Kalinke, R. Rabelo, A. K. Valdo, C. C. da Silva, F. T. Martins, P. Amorós, F. Lloret, M. Julve and D. Cangussu, Dalton Trans., 2018, 47, 11539-11553.

12 T. S. Fernandes, R. S. Vilela, A. K. Valdo, F. T. Martins, E. García-España, M. Inclán, J. Cano, F. Lloret, M. Julve, H. O. Stumpf and D. Cangussu, Inorg. Chem., 2016, 55, 2390-2401.

13 J. Maciel, L. Kalinke, A. Valdo, F. Martins, R. Rabelo, N. Moliner, J. Cano, M. Julve, F. Lloret and D. Cangussu, J. Braz. Chem. Soc., 2019, 30, 2413-2429.

14 T. L. Oliveira, L. H. G. Kalinke, E. J. Mascarenhas, R. Castro, F. T. Martins, J. R. Sabino, H. O. Stumpf, J. Ferrando, M. Julve, F. Lloret and D. Cangussu, Polyhedron, 2014, 81, 105-114.

15 T. T. da Cunha, V. M. M. Barbosa, W. X. C. Oliveira, C. B. Pinheiro, E. F. Pedroso, W. C. Nunes and C. L. M. Pereira, Polyhedron, 2019, 169, 102-113.

16 T. T. da Cunha, V. M. M. Barbosa, W. X. C. Oliveira, E. F. Pedroso, D. M. A. García, W. C. Nunes and C. L. M. Pereira, Inorg. Chem., DOI:10.1021/acs.inorgchem.0c01628.

17 K. Yoneda, Y. Hori, M. Ohba and S. Kitagawa, Chem. Lett., 2008, 37, 64-65.

18 A. Li, Y. Li, L.-M. Chamoreau, C. Desmarets, L. Lisnard and Y. Journaux, Eur. J. Inorg. Chem., 2020, 2020, 3311-3319.

19 R. Ruiz, J. Faus, F. Lloret, M. Julve and Y. Journaux, Coordination Chemistry Reviews, 1999, 193-195, 1069-1117.

20 E. Pardo, C. Train, R. Lescouëzec, Y. Journaux, J. Pasán, C. Ruiz-Pérez, F. S. Delgado, R. Ruiz-Garcia, F. Lloret and C. Paulsen, Chem. Commun., 2010, 46, 2322.

21 E. Pardo, R. Ruiz-Garcia, F. Lloret, J. Faus, M. Julve, Y. Journaux, M. A. Novak, F. S. Delgado and Catalina. Ruiz-Perez, Chem. Eur. J., 2007, 13, 2054-2066, S2054/1-S2054/5.

22 Y. Pei, M. Verdaguer, O. Kahn, J. Sletten and J. P. Renard, Inorg. Chem., 1987, 26, 138-143.

23 F. Lloret, M. Julve, J. Cano, R. Ruiz-Garcia and Emilio. Pardo, Inorg. Chim. Acta, 2008, 361, 3432-3445.

24 J. R. Neilson, D. E. Morse, B. C. Melot, D. P. Shoemaker, J. A. Kurzman and R. Seshadri, Phys. Rev. B, $2011,83,094418$.

25 O. Kahn, Y. Pei, M. Verdaguer, J.-P. Renard and J. Sletten, J. Am. Chem. Soc., 1988, 110, 782-789.

26 H. O. Stumpf, Y. Pei, L. Ouahab, F. Le Berre, E. Codjovi and O. Kahn, Inorg. Chem., 1993, 32, 5687-5691.

27 H. O. Stumpf, Y. Pei, O. Kahn, J. Sletten and J. P. Renard, J. Am. Chem. Soc., 1993, 115, 6738-6745.

28 P. J. Van Koningsbruggen, O. Khan, K. Nakatani, Y. Pei, J. P. Renard, M. Drillon and P. Legoll, Inorg. Chem., 1990, 29, 3325-3331. 
29 C. L. M. Pereira, A. C. Doriguetto, C. Konzen, L. C. Meira-Belo, U. A. Leitão, N. G. Fernandes, Y. P. Mascarenhas, J. Ellena, A. L. Brandl, M. Knobel and H. O. Stumpf, Eur. J. Inorg. Chem., 2005, 5018-5025.

30 E. Pardo, R. Ruiz-Garcia, F. Lloret, J. Faus, M. Julve, Y. Journaux, F. Delgado and Catalina. Ruiz-Perez, Adv. Mater., 2004, 16, 1597-1600.

31 J. Ferrando-Soria, D. Cangussu, M. Eslava, Y. Journaux, R. Lescouëzec, M. Julve, F. Lloret, J. Pasan, C. Ruiz-Perez, E. Lhotel, C. Paulsen and Emilio. Pardo, Chem.-Eur. J., 2011, 17, 12482-12494, S12482/1S12482/8.

32 R. Georges, J. Curély, J. C. Gianduzzo, X. Qiang, O. Kahn and Y. Pei, Physica B: Condensed Matter, 1988, 153, 77-84.

33 Y. Pei, O. Kahn, J. Sletten, J. P. Renard, R. Georges, J. C. Gianduzzo, J. Curely and Q. Xu, Inorg. Chem., 1988, 27, 47-53.

34 C. Mathoniere, O. Kahn, J. C. Daran, H. Hilbig and F. H. Koehler, Inorg. Chem., 1993, 32, 4057-4062.

35 F. Palacio, in Magnetic Molecular Materials, D. Gatteschi, O. Kahn, J. Miller, F. Palacio, Dordrecht Boston London, Kluwer Academic Publishers., 1991, vol. 198, pp. 1-34.

36 BrukerAXS Inc, Madison, Wisconsin, USA., 1998.

37 R. H. Blessing, Acta Cryst A, 1995, 51, 33.

38 G. M. Sheldrick, Acta Cryst A, 2015, 71, 3-8.

39 G. M. Sheldrick, Acta Cryst C, 2015, 71, 3-8.

40 O. V. Dolomanov, L. J. Bourhis, R. J. Gildea, J. a. K. Howard and H. Puschmann, J Appl Cryst, 2009, 42, 339-341.

41 A. L. Bail, Powder Diffraction, 2005, 20, 316-326.

42 J. Rodríguez-Carvajal, Physica B: Condensed Matter, 1993, 192, 55-69.

43 J. M. Kosterlitz and D. J. Thouless, J. Phys. C: Solid State Phys., 1973, 6, 1181. 
Supplementary information
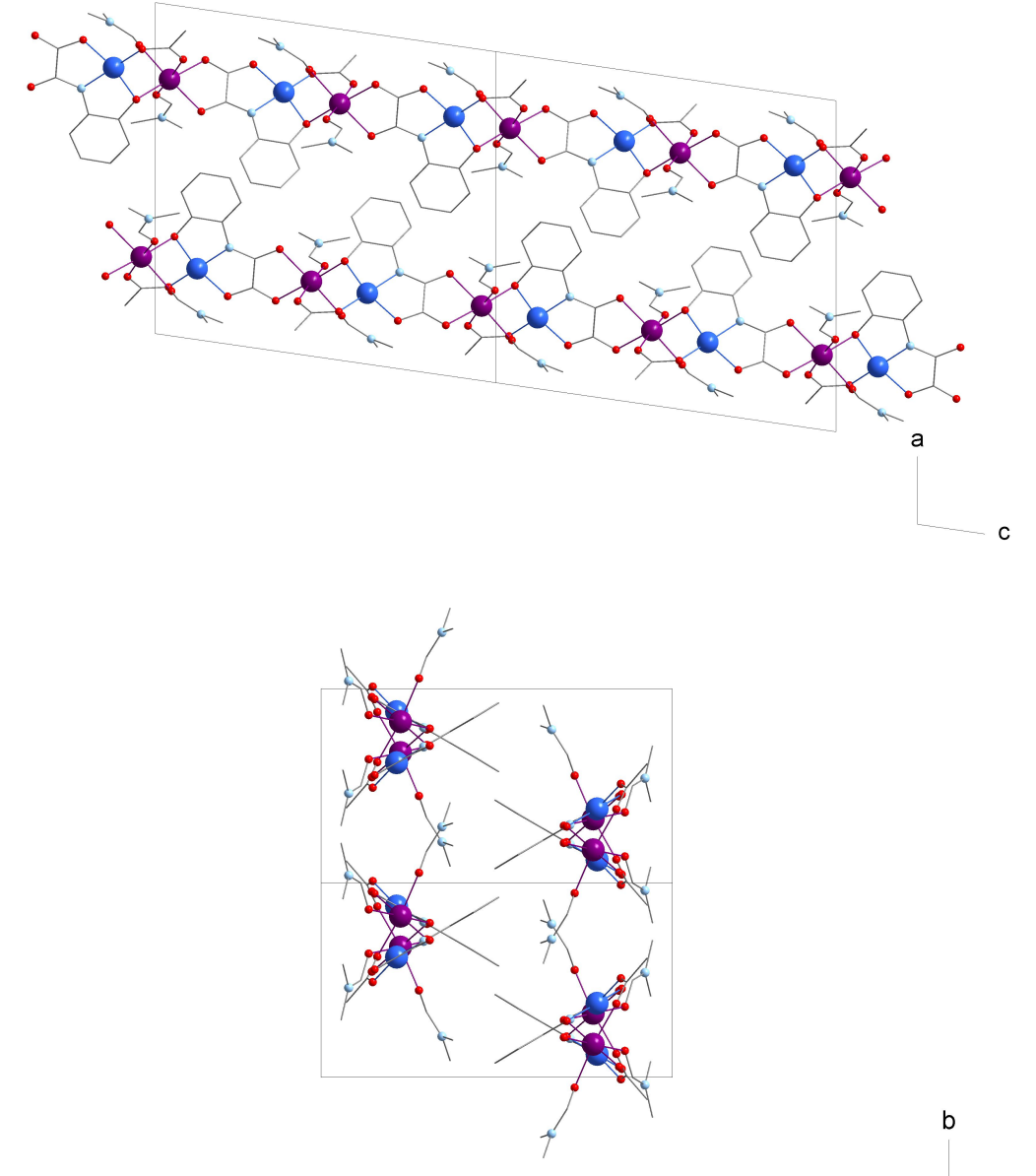

a

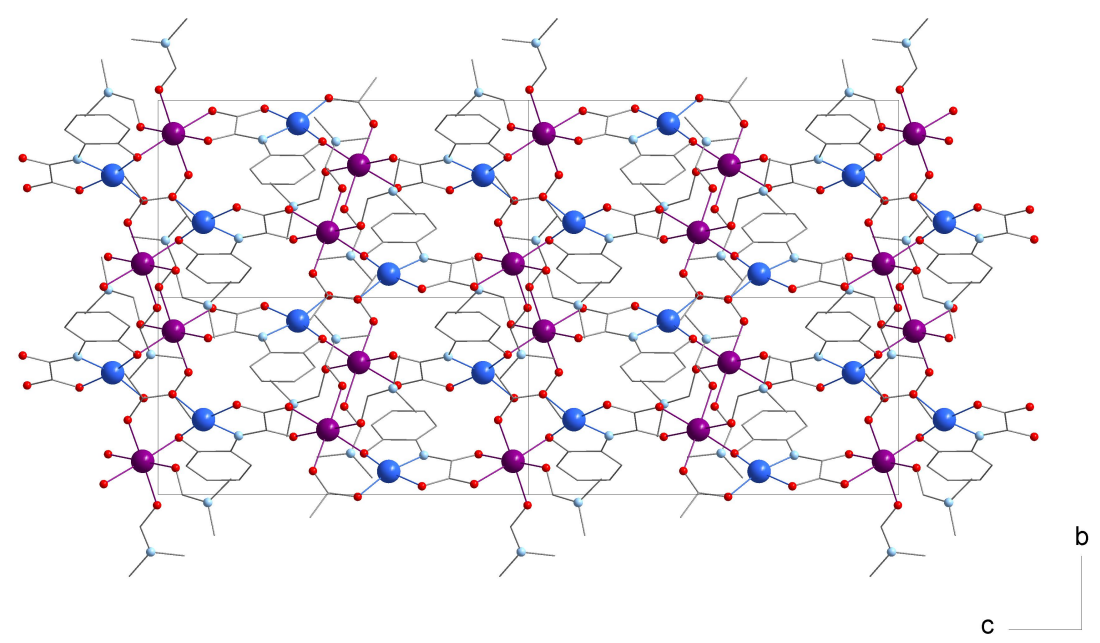




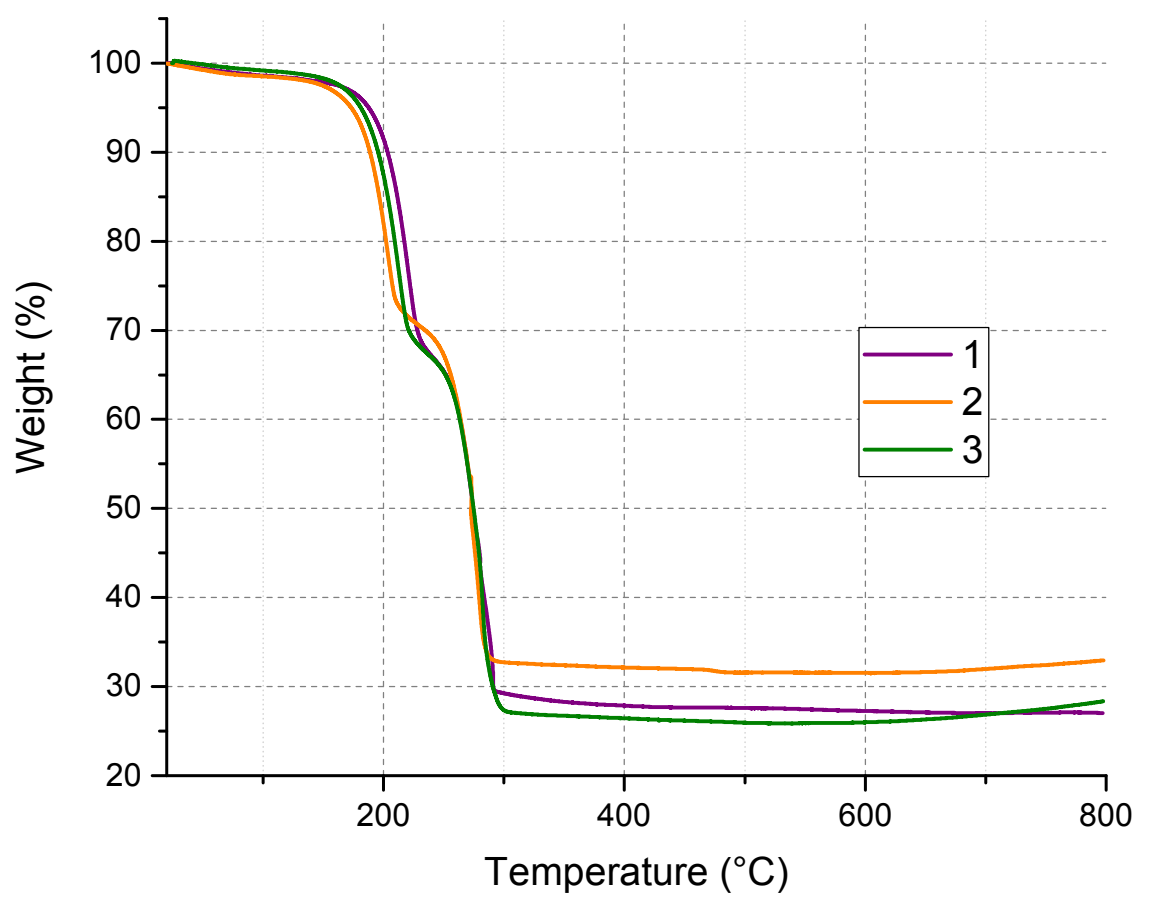

TGA of compounds 1-3 performed under air at $5^{\circ} \mathrm{C} / \mathrm{min}$.

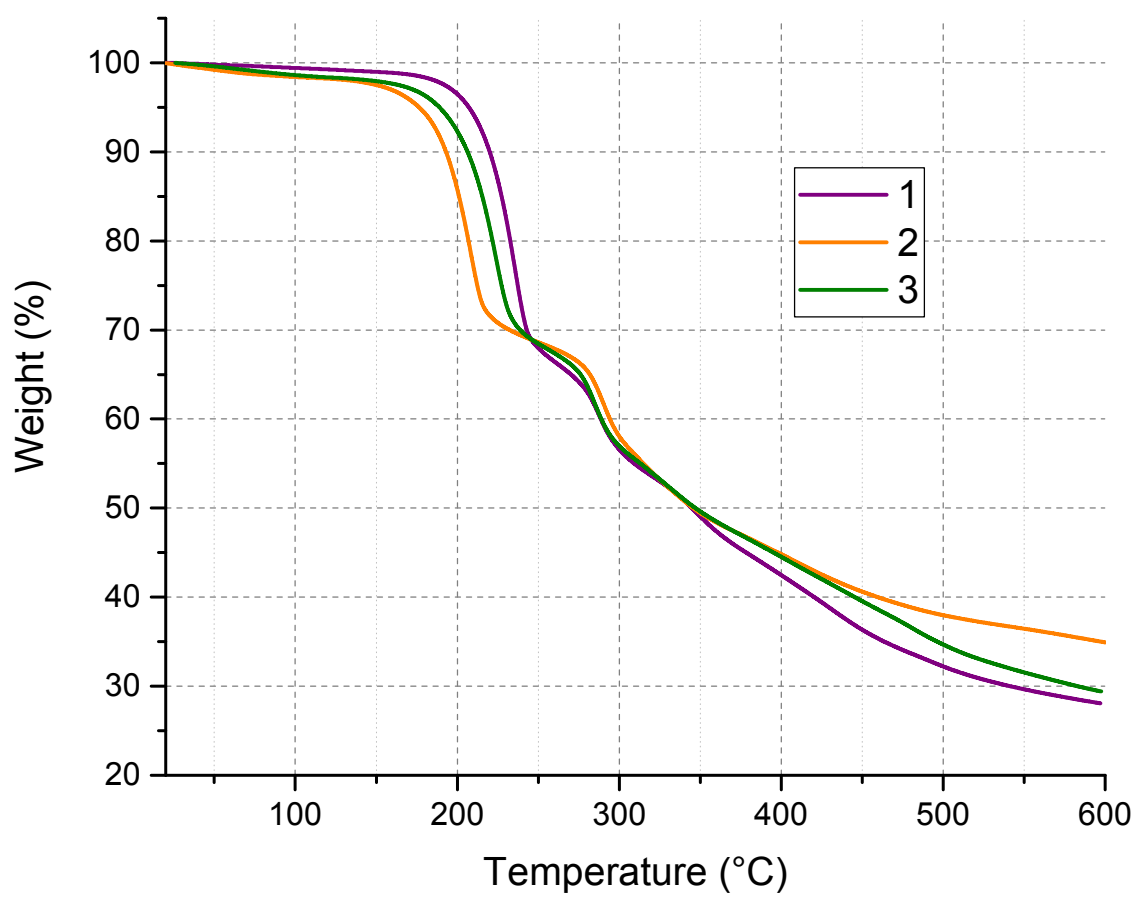




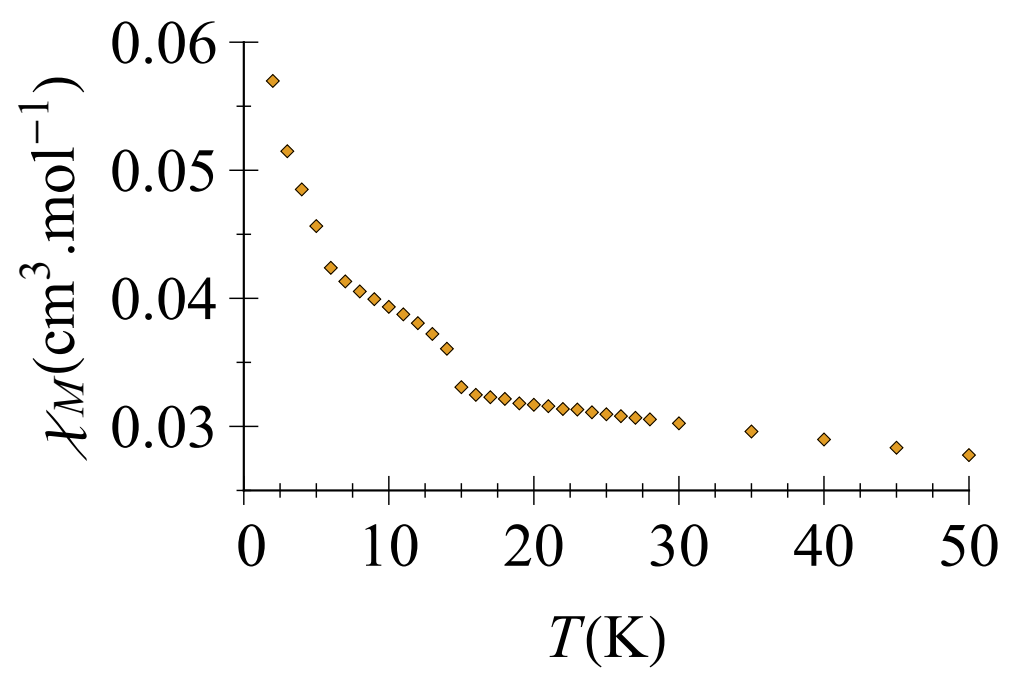

Thermal dependence of the $\chi_{\mathrm{M}}$ of 1 measured at $200 \mathrm{Oe}$

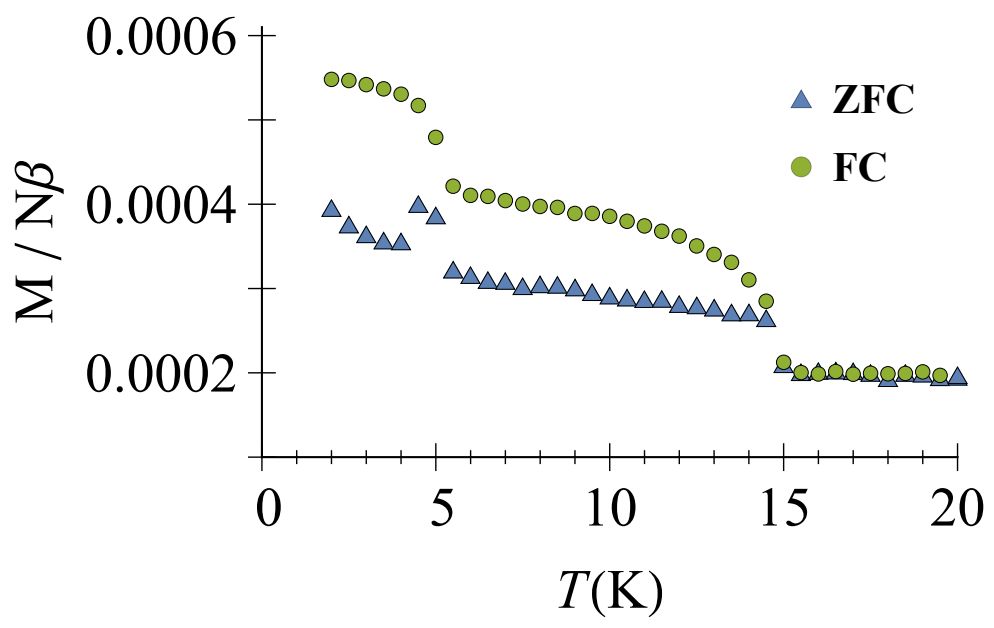

ZFC/FC curves measured at 30 Oe for 1 .

\begin{tabular}{c|c|c|c|} 
& Ising & $X Y$ & Heisenberg \\
\hline 1D & No & No & No \\
\hline 2D & Yes & KT transition & No \\
\hline 3D & Yes & Yes & Yes \\
\hline
\end{tabular}

